\title{
A Plastic Bag Consumed by a Common Indian Krait, Bungarus caeruleus (Schneider 1801)
}

\author{
Rahul V. Deshmukh ${ }^{1}$, Sagar A. Deshmukh², Swapnil A. Badhekar ${ }^{3}$, and Shubham D. Katgube ${ }^{4}$ \\ ${ }^{1}$ H. No. 26, Teacher colony, Brahmani - Kalmeshwar, Nagpur, M.S. - 441501 (rahul30.snake@gmail.com) \\ ${ }^{2}$ Behind Potdar Nursing Home, Kalmeshwar, Nagpur, M.S. - 441501 (sd.snakefriend@gmail.com) \\ ${ }^{3}$ Tiwaskarwadi, Raipur, Hingana, Nagpur, M.S. - 441110 (swapnilbadhekar86@gmail.com) \\ ${ }^{4}$ Saoner ring road Brahmani, Kalmeshwar, Nagpur, M.S. - 441501 (shubham95.snake@gmail.com)
}

$\mathrm{K}^{\mathrm{r}}$

raits in the elapid genus Bungarus Daudin 1803 range widely throughout southeastern Asia (Abtin et al. 2014). Of the 16 known species (Abtin et al. 2014; Wallace et al. 2014), 15 are restricted to southern portions of southeastern Asia (Slowinski 1994; David and Ineich 1999; Kuch et al. 2005) and one to Iran (Abtin et al. 2014). The Common Krait (Bungarus caeruleus) is the only species in peninsular India south of the Ganges Basin (Smith 1943). It is abundant, especially in central India (Whitaker and Captain 2004; Deshmukh et al. 2015) and in the Nagpur District (Deshmukh et al. 2015, 2016). Kraits are nocturnally active and are known to feed on snakes (even other kraits) but also on rodents, lizards, and frogs (Whitaker and Captain 2008). Herein we record an instance of a Common Krait consuming a plastic bag.

At 0800 h on 22 August 2017, S. Katgube encountered a subadult Bungarus caeruleus in rock debris (Fig. 1) in the Kalmeshwar Tehsil of Nagpur District, Maharashtra, India $\left(20^{\circ} 17^{\prime} 08.24^{\prime \prime} \mathrm{N}, 20^{\circ} 20^{\prime} 14 " \mathrm{E}\right)$. The snake (approximate total length $635 \mathrm{~mm}$ ) was trying to expel a black plastic bag through its cloaca. The ingested plastic bag, $297.04 \mathrm{~mm}$ in length, was compacted in the posterior part of the body (Fig. 2) and the snake seemed unable to expel it. The animal appeared to be exhausted and its movements were restricted

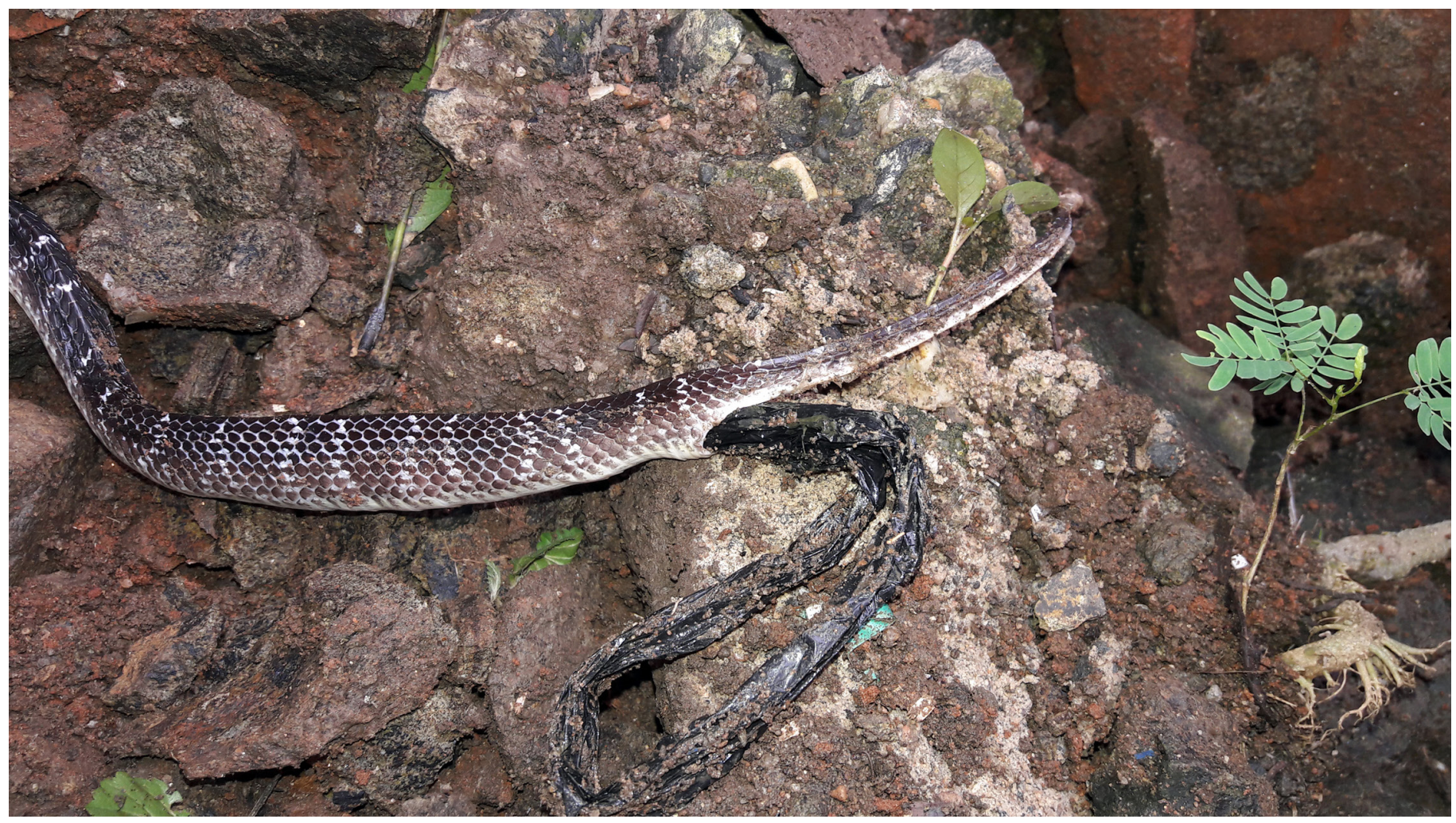

Fig. 1. A subadult Common Krait (Bungarus caeruleus) trying to expel a plastic bag. Photograph by Shubham Katgube. 
by the bag. After waiting for one hour, we began to pull out the bag. We had to apply considerable force (Fig. 3) and believe it would have been impossible for the snake to expel it without assistance. We believe that the ingestion of the plastic bag, whether taken secondarily or accidentally, would likely have been fatal to the snake. The bag probably smelled like

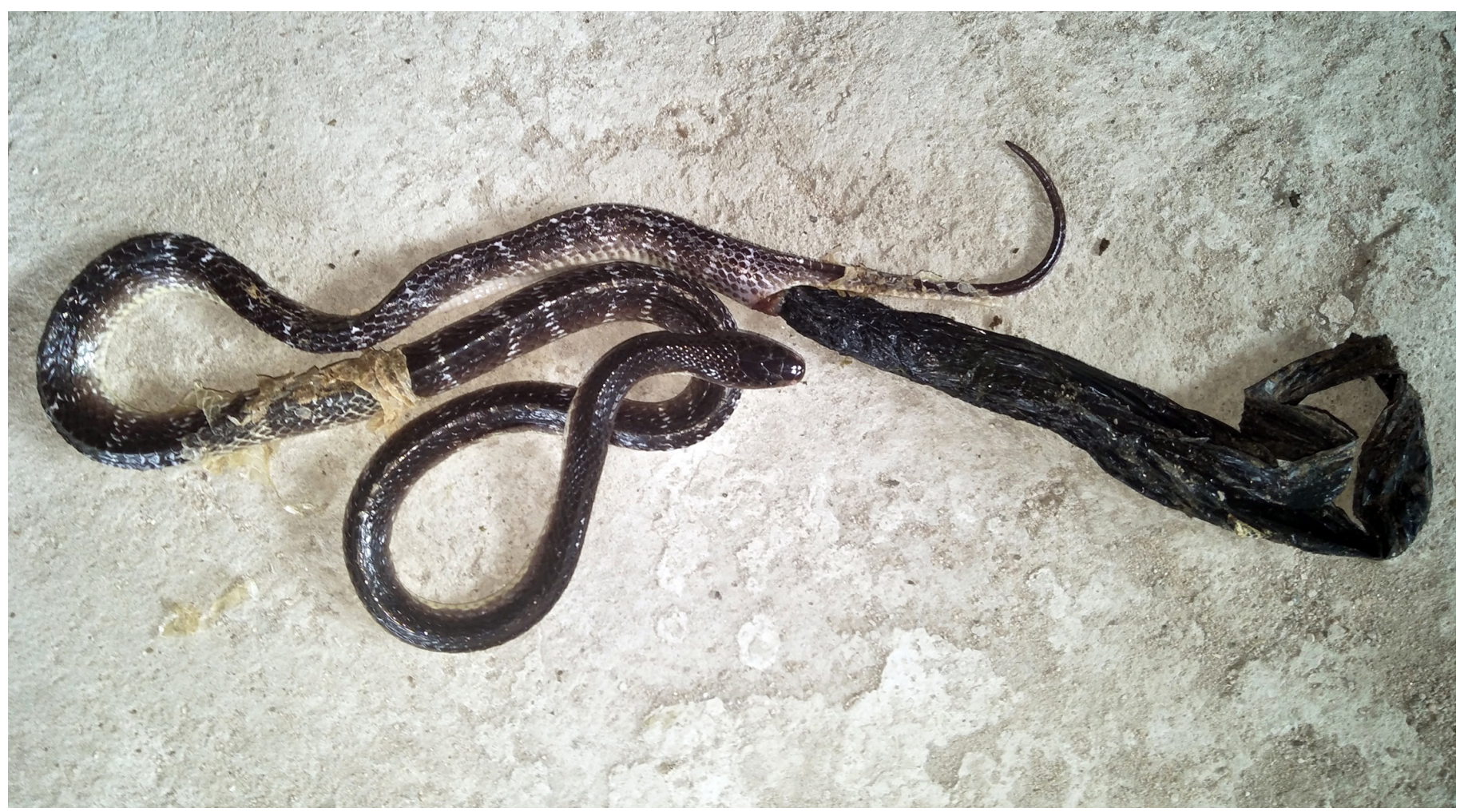

Fig. 2. A subadult Common Krait (Bungarus caeruleus) clearly showing the ingested black plastic bag. Photograph by Sagar Deshmukh.

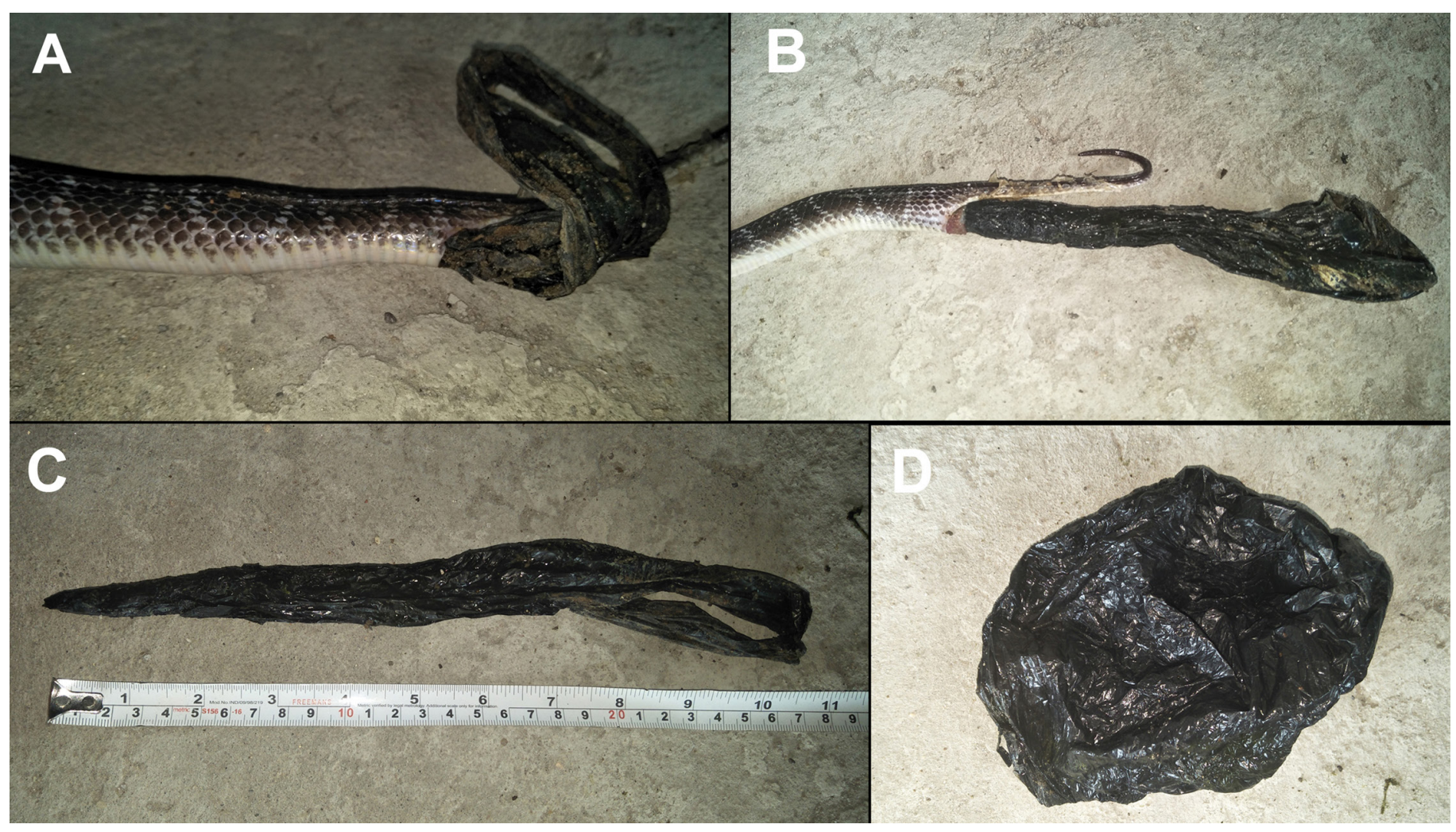

Fig. 3. A subadult Common Krait (Bungarus caeruleus) that had consumed a plastic bag: (A) One-third of the bag had been expelled when the snake was first encountered; (B) half of the bag removed after the authors intervened, (C \& D) the plastic bag after removal. Photographs by Sagar Deshmukh. 
meat as such bags are frequently used to carry non-vegetable items. Bungarus caeruleus relies heavily on its olfactory sense (Deshmukh et al. 2016) and probably was attracted by the scent emanating from the bag.

Snakes typically are carnivorous, with various species consuming a variety of invertebrate and vertebrate prey, often in accordance with the size of predator and prey (e.g., Green 1997). Recently, occurrences of herbivory, consumption of inanimate objects, and scavenging have been reported. Lilywhite et al. (2008) mentioned the consumption of marine plants by a Florida Cottonmouth (Agkistrodon conanti). Mookhergy (1946) described an Indian Python (Python molurus) that had consumed four mangoes infested with insect larvae. Irvine (1953) reported a snake feeding on the yellow fruit of Memordica foetida, a perennial African Vine. Similarly, Dalziel (1937) recorded snakes feeding on fruit under Vitex micrantha, a tropical African tree. Perry (1954) noted that her pet Leopard Snake (Zamenis situla) opportunistically swallowed cheese rinds before reverting to its normal carnivorous diet. Recently, Sharma et al. (2016) reported the instance of an Oriental Ratsnake (Ptyas mucasa) feeding on an onion and consuming a rolled piece of cloth. D'Abreu (1911) reported the presence of stones in the stomach of a Checkered Keelback (Xenocrophis piscator) and speculated that it might serve a similar purpose as stones consumed by crocodiles and birds. Scavenging also has been reported in a number of species (e.g., DeVault and Krochmal 2002). Lillywhite et al. (2002) described Florida Cottonmouths (Agkistrodon conanti) feeding on dead fish dropped by birds and moving to an intertidal zone to feed on dead fish. Ayres (2012) studied scavenging behavior in the genus Natrix and found N. natrix and $N$. maura feeding on the carcasses of newts. Pandirkar et al. (2015) recorded a Common Kukri Snake (Oligodon arnensis) scavenging on a road-killed Garden Lizard (Calotes versicolor). Monopatra (2011) and Deshmukh et al. (2016) documented scavenging behavior in Bungarus caeruleus.

Plastic bags affect wildlife in both marine and terrestrial environments. Plastic bags, once ingested, cannot be digested or easily passed. Plastic in the gut can prevent digestion and lead to a slow and painful death. Such incidents could easily affect other species. In the example described herein, the consumed plastic bag halts the digestion and restricts movement so that the snake becomes an easy meal for another predator or scavenger, which could in turn suffer the same consequences.

\section{Acknowledgements}

For help in various capactities, we thank Dr. B.V. Jadhav (Satara); Rahul Khot, Curator, BNHS; Mr. Vithoba Hegade, BNHS; Dinesh Kathe; Manish Buche; Sunil Kanchane; Sarang Hadke; Sushil Pillewa; Mahesh Thawkar; Ajit Deshmukh; Ankush Kukde; Lalit Nehare; Swapnil Bhondawe; and Tushar Thakur.

\section{Literature Cited}

Abtin, E., G. Nilson, A. Mobaraki, A.A. Hosseini, and M. Dehgannejhad. 2014. A new species of krait, Bungarus (Reptalia, Elapidae, Bungarinae) and the first record of that genus in Iran. Russian Journal of Herpetology 21: 243-250.

Ayres, C. 2012. Scavenging in the genus Natrix. Acta Herpetologica 7: 171-174.

D’Abreu, E.A. 1911. Do snakes swallow stones? The Journal of the Bombay Natural History Society 21: 281.

Dalziel, J.M. 1937. The Useful Plants of West Tropical Africa. Crown Agent for the Colonies, London, UK.

David, P. and I. Ineich. 1999. Les serpents venimeux du monde: systématique et repartition. Dumerilia 3: 1-499.

Deshmukh, R.V., S.A. Deshmukh, and S.A. Badhekar. 2015. Rescued records of snakes from Nagpur District, Maharashtra with data on unrecorded species. Reptile Rap 17: 34-46.

Deshmukh, R.V., S.A. Deshmukh, and S.A. Badhekar. 2016. A second record of scavenging behavior in the Common Indian Krait (Bungarus Caeruleus [Schneider 1801]) from India. Reptiles \& Amphibians 23: 169-170.

DeVault, T.L. and A.R. Krochamal. 2002. Scavenging by snakes: An examination of the literature. Herpetologica 58: 429-436.

Green, H.W. 1997. Snakes: The Evolution of Mystery in Nature. University of California Press, Berkeley.

Irvin, F.R. 1953. Herbivorous snakes. British Journal of Herpetology 1: 173.

Kuch, U., D. Kizirian, Q.T. Nguyen, R. Lawson, M.A. Donnelly, and D. Mebs. 2005. A new species of krait (Squamata: Elapidae) from the Red River System of northern Vietnam. Copeia 2005: 817-832.

Lillywhite, B.H., C.M. Sheehy III, and M.D. McMcu 2002. Scavenging behaviors of Cottonmouth snakes at island bird rookeries. Herpetological Review 33: 259-261.

Lillywhite, B.H., C.M. Sheehy III, and F. Zaidan III. 2008. Pitviper scavenging at the intertidal zone: An evolutionary scenario for invasion of the sea. BioScience 58: 947-955.

Monopatra, P.P. 2011. Bungarus caeruleus (Common Krait). Scavenging. Herpetological Review 42: 436-437.

Mookerjee, S. 1946. Mango-fruit - On the menu of the Common Python (Python molurus). The Journal of the Bombay Natural History Society 46: 733.

Akshay, P., H. Karve, P. Ghadigaonkar, R. Todankar, A. Kuwar, P. Jangam, P. Bandekar, and A. Mahangade. 2015. First record of scavenging by Oligodon arnensis (Shaw, 1802) from Tungareshwar Wildlife Sanctuary, India. Reptile Rap 17:19-21.

Perry, F.L. 1954. [Correspondence]. British Journal of Herpetology 1: 225.

Sharma, V., A. Sayyad, and R. Bhandari. 2016. Herbivory and inanimate objects in the diet of the Oriental Ratsnake, Ptyas Mucosa (Linnaeus 1758) Reptiles \& Amphibians 23: 102-103.

Slowinski, J.B. 1994. A Phylogenetic analysis of Bungarus (Elapidae) based on morphological characters. Journal of Herpetology 28: 440-446.

Smith, M.A. 1943. The Fauna of British India, Ceylon, and Burma, Including the Whole of the Indo-Chinese Sub-region. Reptilia and Amphibia. Volume III, Serpentes. Taylor and Francis Ltd., London, UK.

Whitaker, R. and A. Captain. 2004. Snakes of India: The Field Guide. Draco Books, Chennai, India. 